Journal for

ImmunoTherapy of Cancer

\title{
Perspectives on COVID-19 and cancer immunotherapy: a review series
}

\author{
Jason D Goldman (D) , ${ }^{1,2,3,4}$ Paolo Antonio Ascierto (1) ${ }^{5}$
}

To cite: Goldman JD, Ascierto PA. Perspectives on COVID-19 and cancer immunotherapy: a review series. Journal for ImmunoTherapy of Cancer 2021;9:e002489. doi:10.1136/jitc-2021-002489

Accepted 01 February 2021
Check for updates

(c) Author(s) (or their employer(s)) 2021. Re-use permitted under CC BY-NC. No commercial re-use. See rights and permissions. Published by BMJ.

${ }^{1}$ Swedish Center for Research and Innovation, Swedish Medical Center, Seattle, WA, USA

${ }^{2}$ Providence St. Joseph Health, Renton, WA, USA

${ }^{3}$ Division of Allergy \& Infectious Diseases, University of Washington, Seattle, WA, USA ${ }^{4}$ Vaccine and Infectious Disease Division, Fred Hutch, Seattle, WA, USA

${ }^{5}$ Istituto Nazionale Tumori IRCCS Fondazione 'G. Pascale', Naples, Italy

\section{Correspondence to}

Dr Paolo Antonio Ascierto; paolo.ascierto@gmail.com
Practically every aspect of modern life has been upended by the ongoing COVID-19 pandemic caused by the novel severe acute respiratory syndrome coronavirus (SARS-CoV-2) that emerged in 2019. Yet, despite substantial disruptions to the dayto-day practices of caring for patients and performing research, the biomedical community as a whole has rallied and adapted. Through creativity, collaboration across disciplines, open communication, and a commitment to the scientific enterprise, the amount of knowledge generated in merely 1 year on an entity that was previously unknown to humans was, to use the word-of-the-year for 2020, unprecedented.

Throughout the outbreak, the immunotherapy community has been both uniquely challenged by circumstances and exceptionally poised to contribute to the global effort. Despite facing extreme obstacles in providing essential lifesaving care to patients with cancer amidst a pandemic, insights from immuno-oncology have been invaluable to the response. Perhaps most prominently, mRNA-based vaccines-now delivering up to $95 \%$ protection rates against SARS-CoV-2 infection in published trials-have a decadeslong history of investigation as potential tumor immunotherapies. Additionally, adaptive trial design, a strength of the oncology community, has been essential to conduct studies with integrity and sufficient power to identify potential benefits of interventions in a disease with diverse presentations and a rapidly shifting standard of care.

Our understanding of COVID-19 has increased quickly, yet many aspects of the disease still remain mysterious. Even though a complete genome sequence of the novel coronavirus was deposited a mere 10 days after the first cluster of pneumonia cases of unknown etiology was reported by the Wuhan Municipal Health Commission, and the timelines for vaccine development through emergency use authorization were record-breaking, important questions remain about the heterogeneity of clinical presentations, durability of immunity, and interactions between the pathology of SARS-CoV-2 and underlying conditions, especially cancer. While it is known that patients with cancer may be more vulnerable to SARS-CoV-2 infection, ${ }^{12}$ disentangling the effects of immunemodulatory therapies versus the underlying malignancy on disease outcomes is challenging. An isolated case report has even emerged of SARS-CoV-2 infection inducing complete remission independent of any interventions in a patient with lymphoma, ${ }^{3}$ further highlighting the complex interplay between the immune system and cancer in COVID-19.

Given the now-established role of dysregulated inflammation in more severe cases of COVID-19, ${ }^{45}$ it will be critical to understand any potential interactions between SARS-CoV-2 pathology and the activities of immunotherapies for patients with cancer. Emerging data indicate that checkpoint inhibitors might not predispose patients with COVID-19 and cancer to worse outcomes, ${ }^{6}$ but further studies are needed to understand the risk-benefit calculation for proceeding with immunotherapy amidst the backdrop of the ongoing pandemic. Additionally, a deeper understanding of protective immunity versus the fulminant inflammation seen in severe COVID-19 will be required to identify appropriate interventions for different stages of the disease course. Although parallels exist between elevated cytokine levels in SARS-CoV-2 and cytokine release syndrome associated with chimeric antigen receptor $\mathrm{T}$ cell therapy, ${ }^{7}$ it is becoming clear that these are distinct conditions and management strategies will diverge.

The aim of this review series is to distill down a portion of the vast torrent of literature through an immunotherapy-focused lens. Authored by leading voices in the immunooncology field, including oncologists, immunologists, and experts from infectious disease 
and virology, these reviews explore basic insights into the immunology of the novel coronavirus, repurposing of immune-based therapies including the effects of immuno-oncology agents, and the affected cancer populations. The invited reviews include deep insights into the anti-SARS-CoV-2 immune response in the manuscript titled, 'Interrogation of the cellular immunome of cancer patients with regard to the COVID-19 pandemic,' as well as a forthcoming paper on parallels and differences between the inflammatory pathology in COVID-19 and secondary to adoptive cell therapy. Immunotherapies including interleukin- 6 modulation and inhibitors of the JAK-STAT pathway will be explored in depth. Special articles on the fruits of many years of work in vaccines and antibody-based antiviral therapies will be covered. Special considerations for practicing oncologists during the pandemic are discussed in 'Severity of COVID-19 in lung cancer patients: evidence and challenges,' and the interaction between SARS-CoV-2 and checkpoint inhibitor therapy in the setting of other malignancies such as melanoma, renal cell carcinoma, and lung cancer will also be covered. Lastly, determinants of COVID-19 severity in patients with cancer and other immunocompromised populations will be surveyed. This series will provide a valuable resource for JITC readers not only as a source for hypothesis generation for future basic and translational studies, but also as initial guidance in clinical decision-making.

The immunotherapy community has been an early leader in calling for rapid information sharing during the pandemic, and the Society for Immunotherapy of Cancer (SITC) has issued several statements and published papers $^{89}$ to assist the global response. We are proud that the journal can contribute to the ongoing efforts to combat the COVID-19 pandemic and optimistic that insights from immunotherapy will be invaluable to the entire biomedical research community not only during the current outbreak, but into the future as well.

Twitter Paolo Antonio Ascierto @PAscierto

Acknowledgments The authors acknowledge Sam Million-Weaver, PhD for medical writing support and Matthew Erickson for project management and editorial assistance.
Contributors PAA and JDG led the development and conceptualization of the JITC COVID-19 and Cancer Immunotherapy series as editors.

Funding The authors have not declared a specific grant for this research from any funding agency in the public, commercial or not-for-profit sectors.

Competing interests PAA-Contracted research: Bristol-Myers Squibb, Roche, Array, Sanofi; Consulting fees: Bristol-Myers Squibb, Roche, Array, Novartis, Merck Serono, Pierre Fabre, Incyte, Medimmune, Syndax, AstraZeneca, Sun Pharma, Sanofi, Idera, Ultimovacs, Sandoz, Immunocore, 4sc, Alkermes, Italfarmaco, Nektar, Boehringer-Ingelheim, Eisai, Regeneron Pharmaceuticals, Daiichi Sankyo, Pfizer, Oncosec; Travel support: Merck Sharp \& Dohme. JDG—Clinical trial research support: Gilead Science, Regeneron Pharmaceuticals, Eli Lilly; Grants: BARDA (administered by Merck), Monogram Biosciences, Viracor, all outside the submitted work.

Patient consent for publication Not required.

Provenance and peer review Commissioned; internally peer reviewed.

Open access This is an open access article distributed in accordance with the Creative Commons Attribution Non Commercial (CC BY-NC 4.0) license, which permits others to distribute, remix, adapt, build upon this work non-commercially, and license their derivative works on different terms, provided the original work is properly cited, appropriate credit is given, any changes made indicated, and the use is non-commercial. See http://creativecommons.org/licenses/by-nc/4.0/.

\section{ORCID iDs}

Jason D Goldman http://orcid.org/0000-0002-3825-6832

Paolo Antonio Ascierto http://orcid.org/0000-0002-8322-475X

\section{REFERENCES}

1 Zhang L, Zhu F, Xie L, et al. Clinical characteristics of COVID-19infected cancer patients: a retrospective case study in three hospitals within Wuhan, China. Ann Oncol 2020;31:894-901.

2 Giannakoulis VG, Papoutsi E, Siempos II. Effect of cancer on clinical outcomes of patients with COVID-19: a meta-analysis of patient data. JCO Glob Oncol 2020;6:799-808.

3 Challenor S, Tucker D. SARS-CoV-2-induced remission of Hodgkin lymphoma. Br J Haematol 2021;192:415.

4 Mathew D, Giles JR, Baxter AE, et al. Deep immune profiling of COVID-19 patients reveals distinct immunotypes with therapeutic implications. Science 2020;369:eabc8511.

5 Su Y, Chen D, Yuan D, et al. Multi-Omics resolves a sharp Disease-State shift between mild and moderate COVID-19. Cell 2020;183:1479-95.

6 Garassino MC, Whisenant JG, Huang L-C, et al. COVID-19 in patients with thoracic malignancies (TERAVOLT): first results of an international, registry-based, cohort study. Lancet Oncol 2020;21:914-22.

7 Pedersen SF, Ho Y-C. SARS-CoV-2: a storm is raging. J Clin Invest 2020;130:2202-5.

8 Ascierto PA ea. SITC Statement on anti-IL-6/IL-6R for COVID-19 Society for Immunotherapy of Cancer (SITC), 2020. Available: https:// www.sitcancer.org/research/covid-19-resources/il-6-editorial

9 Arnaldez FI, O'Day SJ, Drake CG, et al. The Society for immunotherapy of cancer perspective on regulation of interleukin-6 signaling in COVID-19-related systemic inflammatory response. $J$ Immunother Cancer 2020;8:e000930. 